\title{
The small-scale structure of VHF mesospheric summer echo layers observed at mid-latitudes
}

\author{
D. A. Hooper, L. Thomas \\ Department of Physics, University of Wales, Aberystwyth, SY23 3Bz, UK
}

Received: 3 September 1996 / Revised: 10 February 1997 / Accepted: 11 March 1997

\begin{abstract}
The VHF radar system at Aberystwyth $\left(52.4^{\circ} \mathrm{N}, 4.1^{\circ} \mathrm{E}\right)$ has been used to make high-timeresolution, multi-beam observations of mesospheric summer echo layers. These show that the altitude and the sense of vertical movement of the layers can vary over time-scales of minutes and horizontal scales of kilometres. In general, the altitude profiles of signal-tonoise ratio provide evidence of a bifurcated structure with sharp changes in the horizontal wind vector and vertical velocity, and enhanced spectral width occurring at the bifurcation level. The implications of the smallscale structure for studies of the aspect sensitivity of radar returns are discussed, and the changes in windfield at the bifurcation level are compared with 'wind corners' observed in rocket studies of the mesosphere at polar latitudes.
\end{abstract}

\section{Introduction}

Ecklund and Balsley (1981) were the first to notice the extraordinary nature of mid-summer VHF radar echoes from the polar mesosphere, which have become known as polar mesosphere summer echoes (PMSEs) (Röttger et al., 1988). They are observed predominantly between altitudes of 80 and $90 \mathrm{~km}$, in the vicinity of the mesopause, and have radar signal strengths which are typically 20-30 dB stronger than those of non-summer polar mesospheric echoes (Ecklund and Balsley, 1981; Balsley et al., 1983; Czechowsky et al., 1989). The nature of the latter echoes (Ecklund and Balsley, 1981) is similar to that of mesospheric echoes observed at equatorial latitudes throughout the year (Harper and Woodman, 1977); both are, in general, confined to the 60-80-km altitude region.

Correspondence to: $\mathrm{L}$. Thomas
Mesospheric echoes observed at mid-latitudes have been found to show a similar seasonal variation to that seen at polar latitudes (Czechowsky et al., 1979; Thomas et al., 1996). The term mesospheric summer echoes (MSEs) will subsequently refer to observations at midlatitudes. Noticeable differences between MSEs and PMSEs are their duration and continuity. The former have generally only been observed for a maximum of a few hours around local noon, much shorter than the local day length, and can appear sporadically within this time (Reid et al., 1989). PMSEs, however, can be much longer lasting and are not confined to any particular time of day, corresponding to the continuous illumination by sun light of the polar mesosphere in mid-summer months (Ecklund and Balsley, 1981; Czechowsky et al., 1989).

Backscatter from Bragg-scale irregularities of refractive index has been invoked as the mechanism responsible for PMSEs observed by VHF radars (Balsley et al., 1983; Czechowsky et al., 1988; Watkins et al., 1988; Inhester et al., 1990; Kelley et al., 1990; Inhester and Ulwick, 1992; Wu and Widdel, 1992). At the altitudes of these echoes, variations in refractive index are dominated by changes in the free electron density (Woodman and Guillen, 1974). An alternative proposal involves partial reflections from sharp changes in refractive index along the radar beam direction which occur over distances of less than the radar wavelength and which extend to the first Fresnel zone transverse to it; this is known as Fresnel reflection (Röttger and La Hoz, 1990; Röttger et al., 1990a). Several authors have suggested the occurrence of the two echo mechanisms in simultaneously occurring layers which are narrowly separated in altitude (Cho et al., 1993; Miller et al., 1993; Swartz et al., 1993; Ulwick et al., 1993). In addition, it seems very likely that partial reflection from several layers randomly distributed in the vertical direction, known as Fresnel scatter (Gage and Balsley, 1980), will occur.

The polar summer mesosphere has been widely studied, both by remote sensing and by in situ measurements. However, the summer mesosphere at midlatitudes remains relatively unexplored. The present 
study will concentrate on MSEs observed by the UK Natural Environment Research Council MST radar facility at Aberystwyth $\left(52.4^{\circ} \mathrm{N}, 4.1^{\circ} \mathrm{W}\right)$. Particular attention will be paid to the small-scale structure of the echo layers, in terms of both time and horizontal distance in Sect. 3, and in terms of altitude in Sect. 4. The consequences of the small-scale variations for the aspect sensitivity of radar returns will be examined in Sect. 5. Although these observations will be compared with apparently analogous phenomena reported at polar latitudes, in Sect. 6, certain differences have already been noted and it remains to be established to what extent the fundamental natures of the polar and mid-latitude echoes and mesopause regions are similar.

\section{Radar measurements}

Some details of the Aberystwyth radar system are given in Slater et al. (1992). It operates at a frequency of $46.5 \mathrm{MHz}$, has a peak transmitted power of $160 \mathrm{~kW}$ and the capability of 32-bit complementary coding. The antenna consists of a $20 \times 20$ array of four element Yagi aerials covering an area of $104 \times 104 \mathrm{~m}$. The radar beam has a one-way half-power half-width of $1.5^{\circ}$ and can be directed in 16 possible pointing directions: vertically and at zenith angles of $4.2^{\circ}, 6^{\circ}, 8.5^{\circ}$ and $12^{\circ}$. The azimuth directions of the radar beam will be referred to in relation to the cardinal points of the compass, although they are rotated $17.3^{\circ}$ anti-clockwise from them.

In the following sections, use will be made of radar observations of MSEs at Aberystwyth during the summers of 1992-1994. Measurements were normally made using transmitted pulse lengths of $8 \mu$ s giving a range resolution of $1.2 \mathrm{~km}$, although the receiver gates the return signal every microsecond, i.e. every $150 \mathrm{~m}$ of range. Throughout each of the three summers, a few observations were also made with $8-\mu$ s pulses and $2-\mu$ s pulse coding, thus giving a range resolution of $300 \mathrm{~m}$. During each cycle of measurements, the radar was steered between five beam directions in the order: vertical, $\mathrm{NE}^{\circ}$, $\mathrm{SE}^{\circ}$, vertical, $\mathrm{NE} 12^{\circ}$ and $\mathrm{SE} 12^{\circ}$. For the measurements carried out during the summer of 1994, SW beams were used instead of the NE beams. In this study, no use will be made of the second vertical beam observation of each cycle. For each beam direction, Doppler spectra were calculated from time-series of 128 points, each of which represented 128 coherently integrated samples. This gave an observation time of $10.5 \mathrm{~s}$ for each beam direction, which with phase switching by relays and data transfer provides a total cycle time of approximately $78 \mathrm{~s}$.

\section{Horizontal and temporal variations of MSE layers}

Figure 1a represents an MSE observed at Aberystwyth on 17 June 1993. In this and subsequent signal-to-noise ratio $(\mathrm{S} / \mathrm{N})$ plots, the altitude profiles, in $\mathrm{dB}$, only show positive values and are set to zero for regions and periods during which the $\mathrm{S} / \mathrm{N}$ is negative. Profiles are shown for each consecutive cycle of radar observation.

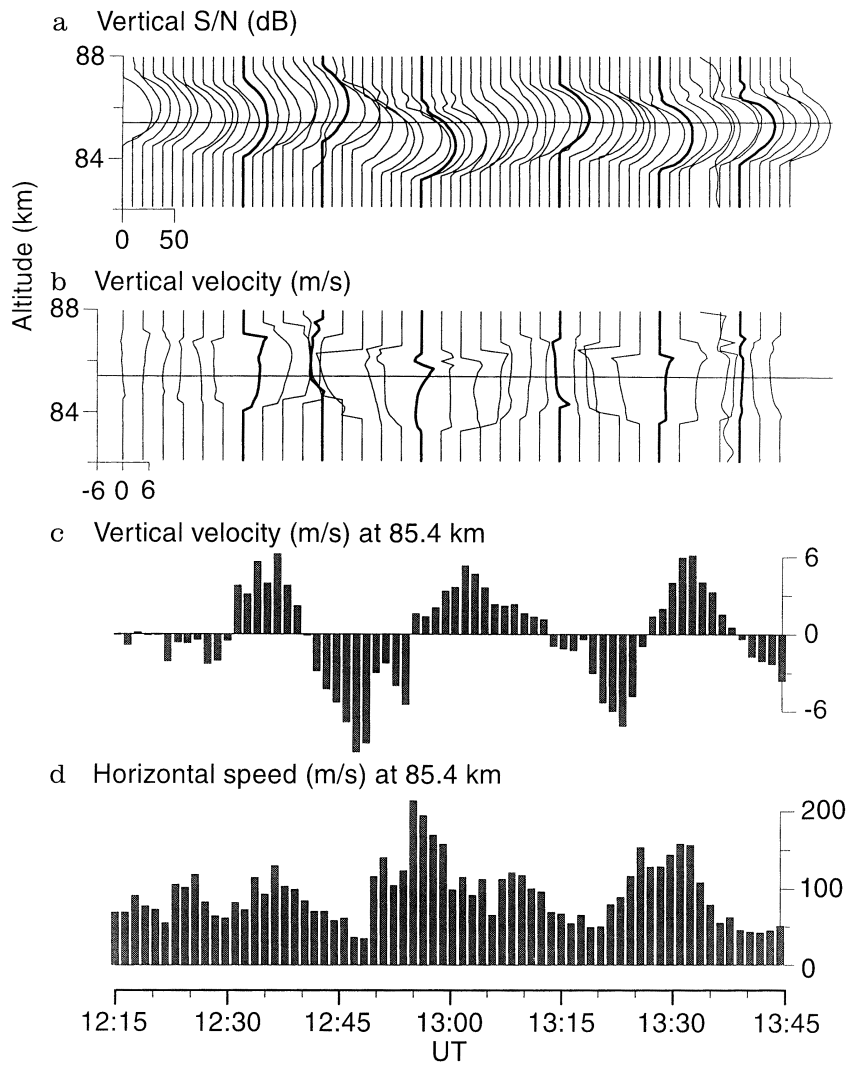

Fig. 1a-d. Altitude profiles of a the vertical $\mathrm{S} / \mathrm{N}$ and $\mathbf{b}$ vertical velocity on 17 June 1993. The bold profiles correspond to the times at which the sense of the vertical velocity reverses. Also shown are the variations in $\mathbf{c}$ of the vertical velocity and $\mathbf{d}$ horizontal speed at an altitude of $85.4 \mathrm{~km}$, indicated by the horizontal lines in $\mathrm{a}$ and $\mathrm{b}$

For the sake of clarity, only every other profile is shown for the vertical (Doppler) velocity in Fig. 1b, and also the velocity-based profiles in Figs. 5-7; furthermore, these profiles are only shown for regions and times where the corresponding vertical $\mathrm{S} / \mathrm{N}$ is greater than $3 \mathrm{~dB}$, and are set to zero elsewhere. The horizontal axes are included for the first of each sequence of profiles; values of zero are aligned with their corresponding times of observation shown on the lower axis. The bold profiles in $\mathrm{a}$ and $\mathrm{b}$ of Fig. 1 highlight the times at which the sense of the vertical velocity reverses. The altitude of the echo layer can clearly be seen to increase when the vertical velocity is positive, and to decrease when it is negative, the magnitudes of the rate of change of altitude being consistent with the vertical velocities; this is a general feature of echo layers observed from Aberystwyth. Kudeki and Stitt (1987) made radar observations of non-summer mesospheric echo layers at mid-latitudes using high-range-resolution frequencydomain interferometry and Franke et al. (1992) used the same technique to observe PMSEs. Both studies found that the rates of change of altitude of the layers were in agreement with the vertical Doppler velocities. In contrast, Miller et al. (1993) reported that the vertical rate of movement of a particular PMSE layer was not related to the corresponding vertical Doppler velocity.

Several radar studies have reported gravity-wave activity, with dominant periods of approximately 
10-20 min, in observations of horizontal velocities (Fritts et al., 1988), vertical velocities (Hoppe et al., 1988; Fritts et al., 1990; Miller et al., 1993; Hoppe and Fritts, 1995) and vertical movements of echo layers (Miller et al., 1993) at polar summer mesopause altitudes. Fritts et al. (1988) suggested that the wave-field is, in general, composed of the superposition of many different wave motions. Gravity-wave activity has also been reported in observations of vertical and horizontal velocities made from Aberystwyth (Thomas and Astin, 1994). Horizontal lines have been superimposed on the profiles of a and b of Fig. 1 at an altitude of $85.4 \mathrm{~km}$; the vertical velocity at this altitude, Fig. 1c, shows clear signs of short-period gravity-wave activity. The horizontal speed at the same altitude, Fig. 1d, also suggests such activity superimposed on a background wind.

It is evident that the observed vertical motion of an echo layer does not necessarily imply vertical movement of a horizontal layer. If the layer is tilted, advection by the background wind through the radar beam would cause an apparent vertical motion. Swartz et al. (1993) proposed such a scenario as the cause of the vertical velocity associated with a particular PMSE observation. However, the pattern shown in Fig. 1c would have to correspond to advection of a wave-like structure to account for the reversals of the tilt with time implied by the changes in sign of the vertical velocity. At an altitude of $85 \mathrm{~km}$, the centres of the $\mathrm{NE}^{\circ}$ and $\mathrm{SE}^{\circ}$ radar volumes are each $8.9 \mathrm{~km}$ from the centre of the equivalent vertical radar volume and $12.6 \mathrm{~km}$ apart from each other; the centres of the $\mathrm{NE} 12^{\circ}$ and $\mathrm{SE} 12^{\circ}$ radar volumes are $17.7 \mathrm{~km}$ from the centre of the equivalent vertical radar volume and $25.0 \mathrm{~km}$ apart from each other. With a typical mean horizontal speed of $100 \mathrm{~m} / \mathrm{s}$, seen in Fig. 1d, the time-delay of a tilt reversal being advected over $25 \mathrm{~km}$ would be of the order of three radar cycles. The changes in altitude of the layer observed in the other four beam directions (NE12 ${ }^{\circ}$, $\mathrm{NE}^{\circ}, \mathrm{SE}^{\circ}$ and $\mathrm{SE} 12^{\circ}$ ) up to the fourth bold profile, i.e. 13:15 UT, Fig. 2, are generally similar to those seen in Fig. 1a and the tilt reversals occur almost simultaneously. This suggests that for this particular MSE layer the vertical velocity relates to real vertical movements associated with gravity waves with horizontal wavelengths considerably in excess of $25 \mathrm{~km}$. After this time, noticeable differences can be seen between the changes in altitude recorded in the different beam directions.

A more striking example of such differences is observed in Fig. 3, which relates to an MSE layer observed on 15 May 1992. The vertical velocity, which is not shown, is again found to be consistent with the rate of change of altitude of the layer observed by the vertical beam, Fig. 3c. However, for this period, the rate, and indeed the sense, are not always the same when observed with different beam directions. Particular attention is drawn to the vertical motion indicated by the MSE within the two time-intervals bounded by the highlighted profiles at 12:36, 12:48 and 12:58 UT. The echo layer observed by the vertical beam shows upward movement within the first interval and downward movement within the second. Although an MSE is not observed contin-

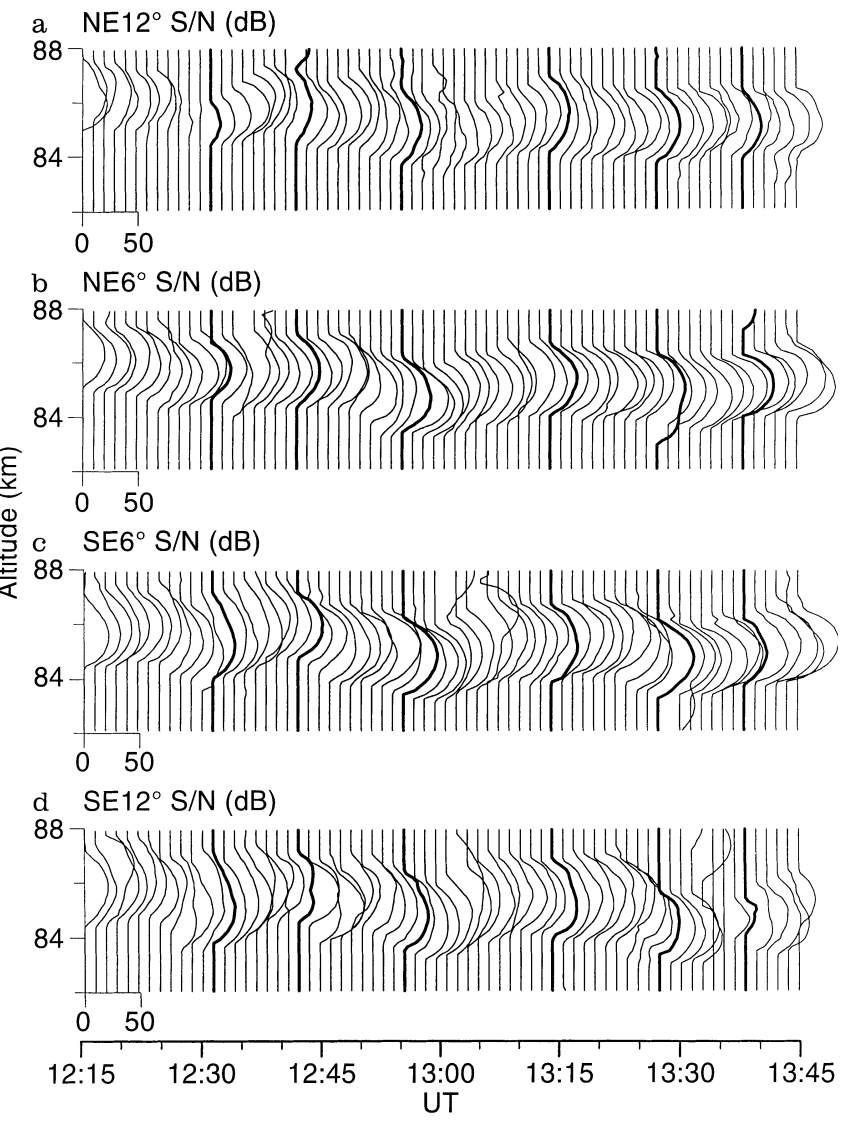

Fig. 2a-d. Altitude profiles of $\mathrm{S} / \mathrm{N}$ for a $\mathrm{NE} 12^{\circ}$, b NE6 ${ }^{\circ}$, c SE6 ${ }^{\circ}$, d SE12 ${ }^{\circ}$ on 17 June 1993. The bold profiles correspond to those in Fig. 1

uously by the $\mathrm{NE} 12^{\circ}$ and $\mathrm{NE} 6^{\circ}$ beams, Fig. $3 \mathrm{a}$ and $\mathrm{b}$, the profiles recorded suggest an upward movement within the first interval and indicate a clear downward movement within the seconds, i.e. they follow the movement of the layer observed by the vertical beam. In contrast, the motion observed by the $\mathrm{SE}^{\circ}$ beam, Fig. 3d, can be seen to be in the opposite sense for each of the time-intervals. An MSE is not seen continuously by the $\mathrm{SE} 12^{\circ}$ beam, Fig. 3e, within the first interval, but the profiles within the second indicate the movement is also in the opposite sense to that shown by the vertical beam. In such a case, it is not possible to determine whether the vertical motion represents a tilted structure being advected by a horizontal wind or actual vertical motion of a horizontal layer. In the latter case, the results for the five beam directions could imply that the MSE is associated with a gravity wave with a wave front aligned in the NE direction, propagating in either the SE or NW direction and with a horizontal half-wavelength of at least $8.9 \mathrm{~km}$, the horizontal separation between the vertical and $\mathrm{SE}^{\circ}$ radar volumes. In this connection, Rüster et al. (1996) showed that the heights of maximum power of a PMSE observed in beams directed vertically and at zenith angles of $8^{\circ}$ in northerly and southerly directions showed time variations consistent with the presence of a gravity wave of period $9.6 \mathrm{~min}$ and horizontal wavelengths 60 and $50 \mathrm{~km}$ in the north and east directions, respectively, as identified in the simultaneous measurements of the velocity field. 


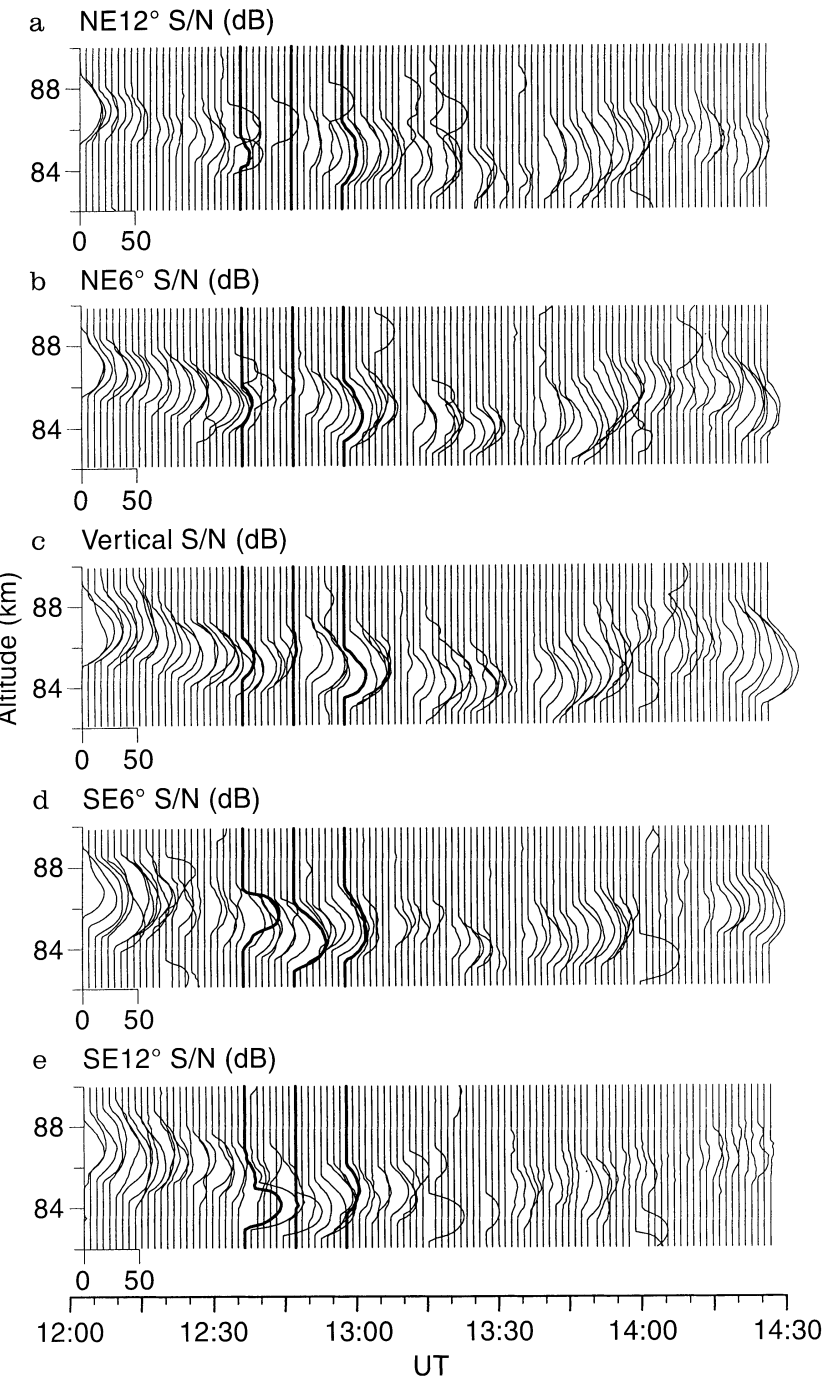

Fig. 3a-e. Altitude profiles of $\mathrm{S} / \mathrm{N}$ for a $\mathrm{NE} 12^{\circ}$, b NE6 ${ }^{\circ}$, c vertical, d SE6 ${ }^{\circ}$ and $\mathbf{e ~ S E} 12^{\circ}$ beams on 15 May 1992 . Attention is drawn to the vertical motions observed in the time-periods 12:36-12:48 UT and 12:48-12:58 UT bounded by the bold profiles

The fact that the altitude of the MSE layer and the sense of its vertical motion can vary over relatively small horizontal distances casts some doubt on the validity of the observed horizontal velocities. These are derived from measurements of radial velocities in the vertical and two orthogonal $6^{\circ}$ beam directions. The contribution of the vertical velocity to the radial velocity along a $6^{\circ}$ radar beam at mesospheric altitudes is, in general, significant. In order to calculate the horizontal components of velocity, it is implicitly assumed that the vertical wind-field is homogeneous over the horizontal distances separating the vertical and off-vertical radar volumes. Within the highlighted time-intervals of Fig. 3, the vertical velocity clearly does not relate to the vertical rate of change of altitude of the echo layer observed by the $\mathrm{SE}^{\circ}$ and $\mathrm{SE} 12^{\circ}$ beams. The calculation of the SE component of horizontal velocity will, therefore, be invalid. It is also generally assumed that the horizontal component of the wind-field is homogeneous over the horizontal distances that separate the different radar volumes. With the radar configuration used in the present investigation, it is not possible to say whether or not such an assumption is valid.

\section{Vertical structure of MSE layers}

Many observations of PMSEs indicate double structures which are narrowly separated in altitude (Czechowsky et al., 1988, 1989; Cho et al; 1993; Lübken et al., 1993; Miller et al., 1993; Ulwick et al., 1993; Inhester et al., 1994). This can also be seen in the altitude profiles of vertical S/N, Fig. 4a, for an MSE observed on 22 June 1994. In this case, use was made of a radar pulse length of $8 \mu$ s with $2 \mu$ s phase coding, thus giving an altitude resolution of $300 \mathrm{~m}$. Two major peaks can be seen which diverge to such an extent that, between 13:15 and 13:50 UT, they represent separate and distinct layers. These subsequently converge and again give the appearance of a single layer with two major peaks as at times prior to 13:15 UT. Miller et al. (1993) reported a similar observation of two PMSE layers initially converging to form a single layer and subsequently diverging to show a double structure.

Figure $4 \mathrm{~b}$ shows profiles of the same data to which a running mean has been applied in altitude over seven consecutive data points in order to reproduce the rangeresolution of $1.2 \mathrm{~km}$ adopted in most of the present study. The two peaks of $\mathrm{S} / \mathrm{N}$ in Fig. 4a, which represent separate layers at 300-m resolution between 13:15 and 13:50 UT, appear as sections of a single layer at $1.2-\mathrm{km}$ resolution in Fig. 4b. Such a structure is a common feature of altitude profiles of vertical $\mathrm{S} / \mathrm{N}$ for MSE layers observed in the present study, such as those shown in Fig. 5a for 2 July 1993. The latter might also show two discrete echo layers if observed at $300-\mathrm{m}$ resolution and this type of MSE layer will subsequently be referred to as a 'bifurcated layer'. Furthermore, prior to 13:15 UT in Fig. 4a, many of the profiles of vertical $\mathrm{S} / \mathrm{N}$ show more than two peaks even at 300 -m-altitude

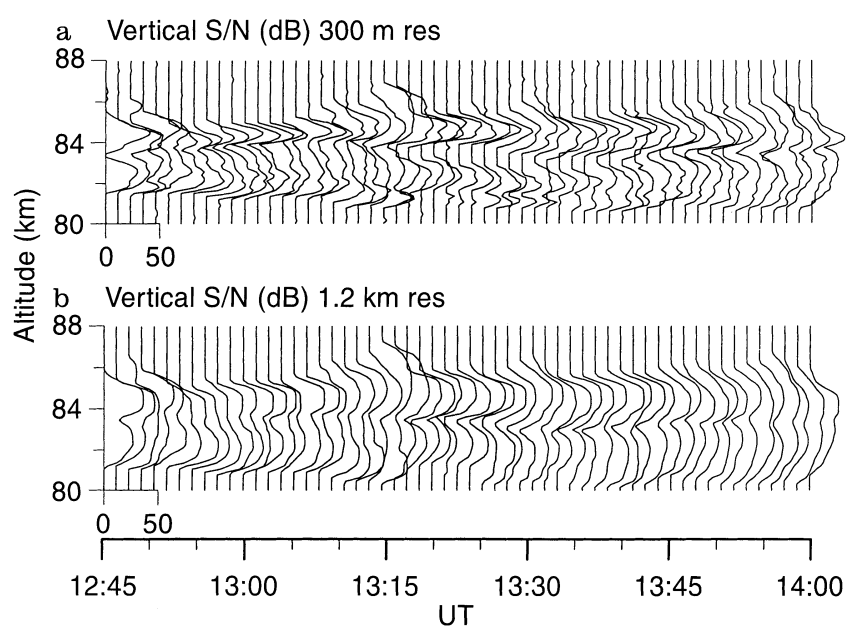

Fig. 4a, b. Altitude profiles of the vertical $\mathrm{S} / \mathrm{N}$ at a $300-\mathrm{m}$-altitude resolution and b 1.2-km-altitude resolution on 22 June 1994 
resolution, and between 13:15 and 13:50 UT each separate layer sometimes shows at least two peaks. It is possible that such peaks might also represent separate layers if radar observations were made with still higher range resolution. In this connection, high-range-resolution observations by Stitt and Kudeki (1990) suggest that the fine structures of mid-latitude winter mesospheric echo layers might be less than $100 \mathrm{~m}$ thick.

In Fig. 5a it can be seen that the peak signal strengths of the two sections of the (coarsely observed) bifurcated

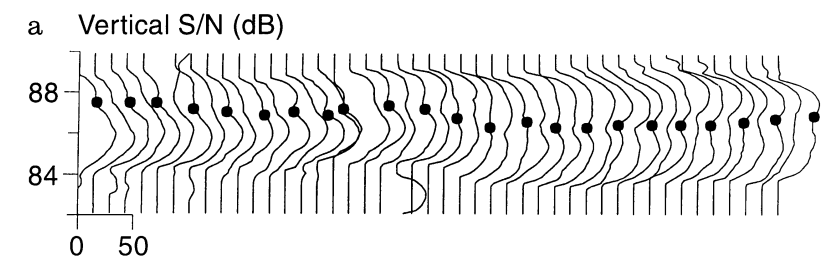

b Horizontal speed $(\mathrm{m} / \mathrm{s})$

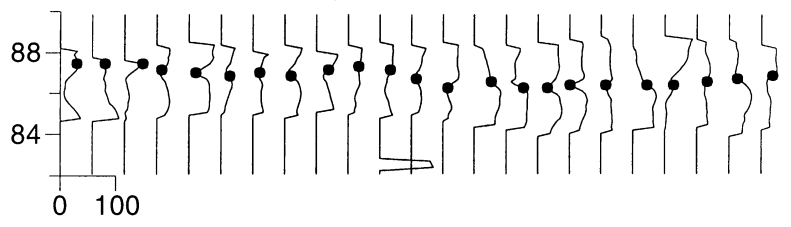

c Horizontal direction (deg)

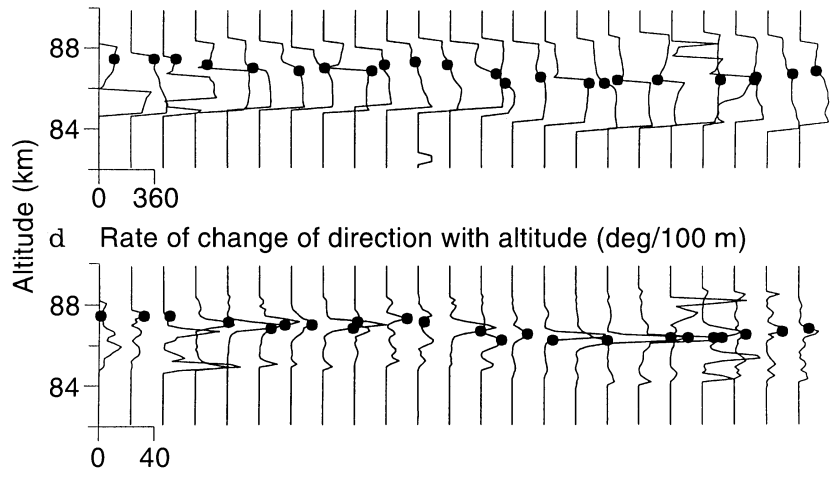

e Vertical shear $(\mathrm{m} / \mathrm{s} / \mathrm{km})$

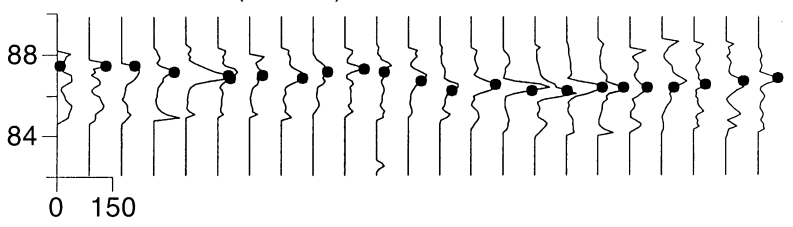

f Vertical spectral width $(\mathrm{m} / \mathrm{s})$

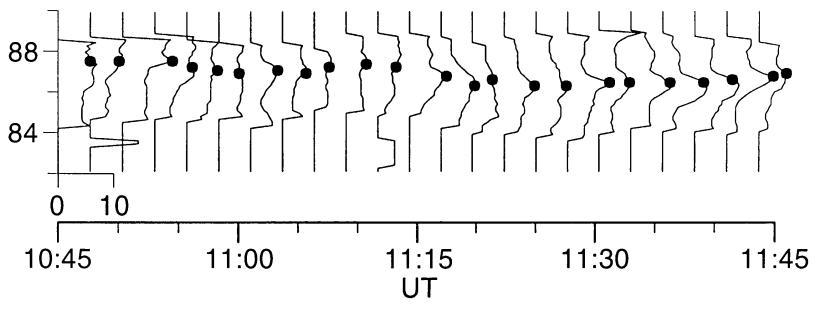

Fig. 5a-f. Altitude profiles of a the vertical $\mathrm{S} / \mathrm{N}$, b horizontal speed, c horizontal direction, $\mathbf{d}$ rate of change of direction with altitude, e vertical shear and f vertical spectral width on 2 July 1993. A direction of $0^{\circ} / 360^{\circ}$ represents wind travelling to the north. The bold dots, shown for every other profile in a, and for every profile in $\mathbf{b}-\mathbf{f}$, mark the altitude of the bifurcation determined subjectively from the profiles in a layer can vary independently with time, neither the upper nor the lower, in general, being dominant. The bold dots, shown for every other profile, identify the altitudes of the bifurcation level, which have been determined subjectively. An indication of the bifurcation is also apparent in the profiles of $\mathrm{S} / \mathrm{N}$ observed in the other four beam directions, which have not been shown. A study of velocity data indicates that the bifurcation of the $\mathrm{S} / \mathrm{N}$ profile has a greater significance than simply marking the separation of two distinct regions of radar returns. Bold dots have been superimposed on the corresponding profiles of horizontal wind speed, Fig. 5b, direction, Fig. 5c, directional shear, Fig. 5d, vertical wind shear, Fig. 5e, and vertical spectral width, Fig. 5f, each at the altitudes of the bifurcation level in Fig. 5a. It can be seen that there is a tendency for sharp changes with altitude of the horizontal wind speed, Fig. 5b, and direction, Fig. 5c, to occur at the bifurcation level; the latter is emphasised in the profiles of directional shear shown in Fig. 5d. The values of the horizontal wind speed and direction tend to be reasonably constant or smoothly varying on either side of the bifurcation level. Moreover, many profiles of wind speed show a distinct minimum at the bifurcation level. As mentioned in the previous section, the validity of the horizontal wind vector is questionable, but it is assumed that the qualitative pattern is correct.

The maximum values of vertical shear, Fig. 5e, which also generally occur at the bifurcation level, can be in excess of $100 \mathrm{~m} / \mathrm{s} / \mathrm{km}$. Since the corresponding temperature profile is not known, profiles of the gradient Richardson number, Ri, cannot be calculated for these data. Nevertheless, for a typical Brunt-Välsälä period of between 5 and $10 \mathrm{~min}$, the minimum vertical shears for the $\mathrm{Ri}<1 / 4$ condition to be met, indicating that the atmosphere is dynamically unstable, would be 40 and $20 \mathrm{~m} / \mathrm{s} / \mathrm{km}$, respectively. The enhanced vertical spectral widths, Fig. 5f, at the bifurcation level also suggest the presence of strong turbulence; this point will be discussed in further detail in Sect. 6.

Figure 6 relates to an MSE observed on 21 June 1993 which again shows some evidence of bifurcation. It can be seen that profiles of the vertical velocity, Fig. $6 \mathrm{~b}$, also show a tendency for sharp changes with altitude at the bifurcation level; the values are again constant or smoothly varying on either side. The bold profiles in a and $b$ of Fig. 6 separate those intervals within which the vertical velocity in the upper section is predominantly more positive than that in the lower section, marked $\mathbf{D}$, and those within which the converse is true, marked $\mathbf{C}$. Although the individual vertical motions of the two sections are difficult to ascertain, it is clear that periods D correspond to times for which the two sections of the MSE are diverging, and hence the total width of the layer is increasing, and periods $\mathbf{C}$ to times for which the sections are converging, and hence the total width of the layer is decreasing.

It has already been suggested that single bifurcated profiles of $\mathrm{S} / \mathrm{N}$ might resolve into two separate layers of MSE at higher range resolution. Referring to the first $\mathbf{C}$ interval in Fig. 6a, between 10:51 and 11:13 UT, the 

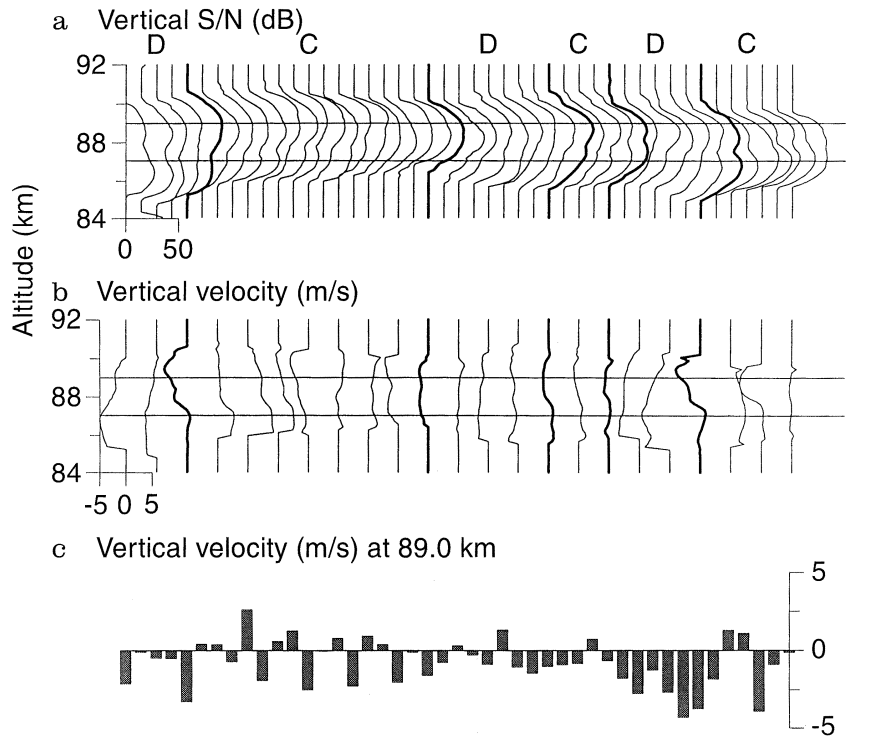

d Vertical velocity $(\mathrm{m} / \mathrm{s})$ at $87.1 \mathrm{~km}$

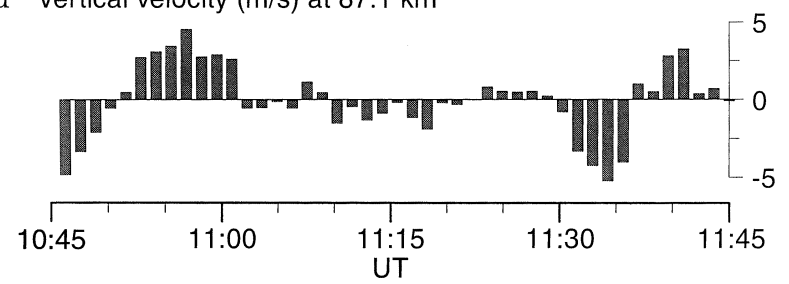

Fig. 6a-d. Altitude profiles of a the vertical $\mathrm{S} / \mathrm{N}$ and $\mathbf{b}$ the vertical velocity on 21 June 1993. The bold profiles separate periods in which the vertical velocity of the upper section is predominantly more positive than that of the lower section, marked $\mathbf{D}$, and periods for which the reverse is true, marked $\mathbf{C}$. Also shown are the variations in vertical velocity at altitudes of $\mathbf{c} 89.0 \mathrm{~km}$ and $\mathbf{d} 87.1 \mathrm{~km}$, indicated by the horizontal lines in the upper and lower sections of the echoes shown in $\mathbf{a}$ and $\mathbf{b}$

separation between the peaks can clearly be seen to reduce to a point at which the MSE shows no bifurcation. It is emphasised that this does not necessarily imply that there is no separation between the two sections, since the bifurcation becomes increasingly indistinct as the separation decreases. Sequences of $\mathrm{S} / \mathrm{N}$ profiles that show no sign of a bifurcation, such as those in Fig. 1a. and Fig. 3, are an exception. It is possible that even these would have displayed greater detail if radar observations had been made at a higher range resolution.

The two horizontal lines superimposed on the profiles a and b of Fig. 6 correspond to altitudes of 89.0 and $87.1 \mathrm{~km}$. For periods when the bifurcation is distinct, these altitudes are, respectively, within the upper and the lower sections of the echo layer. The corresponding vertical velocities are plotted as functions of time for the upper altitude, in Fig. 6c, and for the lower altitude, in Fig. 6d. It can be seen that the vertical velocities at the two altitudes show certain differences. At the lower altitude, there appears to be short-period gravity-wave activity, such as that seen in Fig. 1c, between 10:45 and 11:00 UT and again between 11:30 and 11:45 UT. At the upper altitude, this activity is absent within the first interval and although there are large variations of vertical velocity within the second interval, the pattern, as a function of time, is not so clear as that seen at the lower altitude. Other bifurcated echo layers exist (not shown) for which the vertical-velocity activity is similar in both sections or for which it is greater within the upper section than within the lower section. Similar differences have been observed between the vertical wind-field in the two sections of some PMSEs (Miller et al., 1993; Hoppe and Fritts, 1995).

Although the vertical movements of the two sections of bifurcated-echo layers can show significant differences, they are not entirely independent. The duration of each interval of divergence, $\mathbf{D}$, in Fig. $6 \mathrm{a}$ is too short for the two peaks of $\mathrm{S} / \mathrm{N}$ ever to establish a separation of more than about $3 \mathrm{~km}$. Furthermore, it appears from Fig. 7, which relates to an MSE observed on 19 June 1994, that longer-term trends of vertical movement are common to both sections of the bifurcated layer. Although there are marked differences between the vertical velocities in the upper and lower sections, Fig. 7b, and the width of the layer varies correspondingly, the altitude of the MSE shows an overall downward trend.

It has been proposed in this section that the bifurcation level of echo layers is in some way associated with a level at which the wind-field undergoes a sharp change with altitude. However, the vertical extent of even the widest MSEs is limited to only a few kilometres. It is not therefore clear whether this is a change between two distinct wind-fields, which are otherwise invariant with altitude, or whether it represents part of a more extended variation with altitude.

\section{Aspect sensitivity of radar returns from MSE layers}

Several investigators have reported on the aspect sensitivity of radar returns from MSEs and PMSEs, i.e. the variation of the signal strength as a function of beam-pointing direction at a fixed altitude. In general, attention has been focused on the variations as a

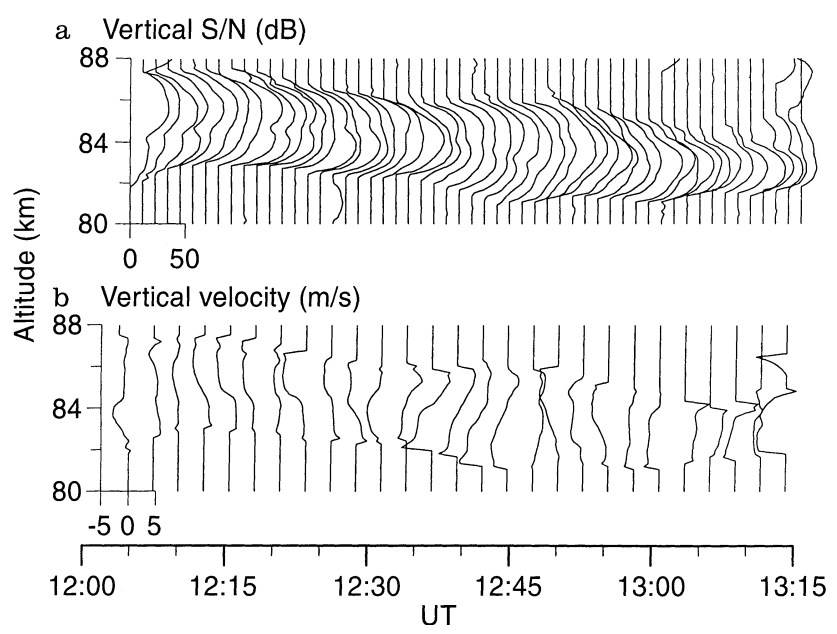

Fig. 7a, b. Altitude profiles of a the vertical $\mathrm{S} / \mathrm{N}$ and $\mathbf{b}$ the vertical velocity, on 19 June 1994 
function of zenith angle and it is assumed that there are no variations as a function of azimuth angle (e.g. Hocking et al., 1986). Layers of radar returns characterised by both high aspect sensitivity (Czechowsky et al., 1988; Reid et al., 1989; Hoppe et al., 1990; Inhester and Ulwick, 1992; Thomas et al., 1992; Cho et al., 1993) and low aspect sensitivity (Thomas et al., 1992; Cho et al., 1993) have been observed. Furthermore, Cho et al. (1993) reported that radar returns from the lower section of a double PMSE showed large aspect sensitivity, whereas those from the upper section showed low aspect sensitivity. Similarly, radar returns from MSEs have been observed to change between high and low aspect sensitivity both in altitude, at a fixed time, and in time, at a fixed altitude (Thomas et al., 1992; Thomas and Astin, 1994).

Figure 8 relates to nine consecutive cycles of observation of a MSE layer on 8 July 1993; the profiles of vertical, $6^{\circ}$ and $12^{\circ} \mathrm{S} / \mathrm{N}$ are shown for the NE, Fig. $8 \mathrm{a}$, and SE, Fig. 8b, azimuths. It can be seen that the aspect sensitivity of radar returns, in each azimuth direction, is highly variable as a function of time and is typically different in these two directions. Moreover, it is not, in general, the same in the upper and lower sections of the bifurcated structure. Such spatial and temporal variations of aspect sensitivity are typical of the present observations of MSEs and could involve tilted layers associated with the short-period gravity waves referred to previously. For radar returns from the troposphere and the lower stratosphere, it is assumed that the aspect sensitivity of radar returns gives a measure of the polar diagram of backscatter from irregularities of refractive index (Hocking et al., 1986; Hooper and Thomas, 1995). It is further assumed that the nature of the scatterers is constant over the time-scales for which measurements are considered, of the order of an hour, and over spatial scales that separate the different radar volumes, the order of one or two kilometers. However, it has been shown in the present study that the altitude and the rate of vertical movement of MSEs and the signal strength of radar returns can vary significantly over time-scales of minutes and over spatial scales of kilometers. It is therefore possible that the radar cross-section, for a given angle of incidence at different azimuths, could also differ over such scales, whether Fresnel reflection or backscatter is responsible for the MSEs. Miller et al. (1993) also concluded that spatial variations were responsible for the large changes in radar signal strength between observations of a PMSE in two different pointing directions.

At the time of the second bold profiles in Fig. 3, significant radar returns are only observed by the SE6 ${ }^{\circ}$ beam. Nevertheless, if an MSE had been observed in the other four directions at this time, the general trends of motion suggest that the layer observed by the NE12 NE6 $6^{\circ}$ and vertical beams would have appeared approximately $2 \mathrm{~km}$ higher than the altitude at which it is observed by the $\mathrm{SE}^{\circ}$ beam; the layer observed by the $\mathrm{SE} 12^{\circ}$ beam would be expected to have occurred at approximately the same altitude as that at which it was observed by the $\mathrm{SE6}^{\circ}$ beam. Since there would be virtually no overlap in altitude between the layers observed by the two groups of beams, the observed aspect sensitivity of the radar returns would obviously be dominated by the variations of the altitude of the layer in the horizontal plane. Spatial variations could also explain the intermittent observation of the MSE in each direction throughout Fig. 3. Although such large differences in altitude of an MSE layer observed in different directions are unusual, marked variations in

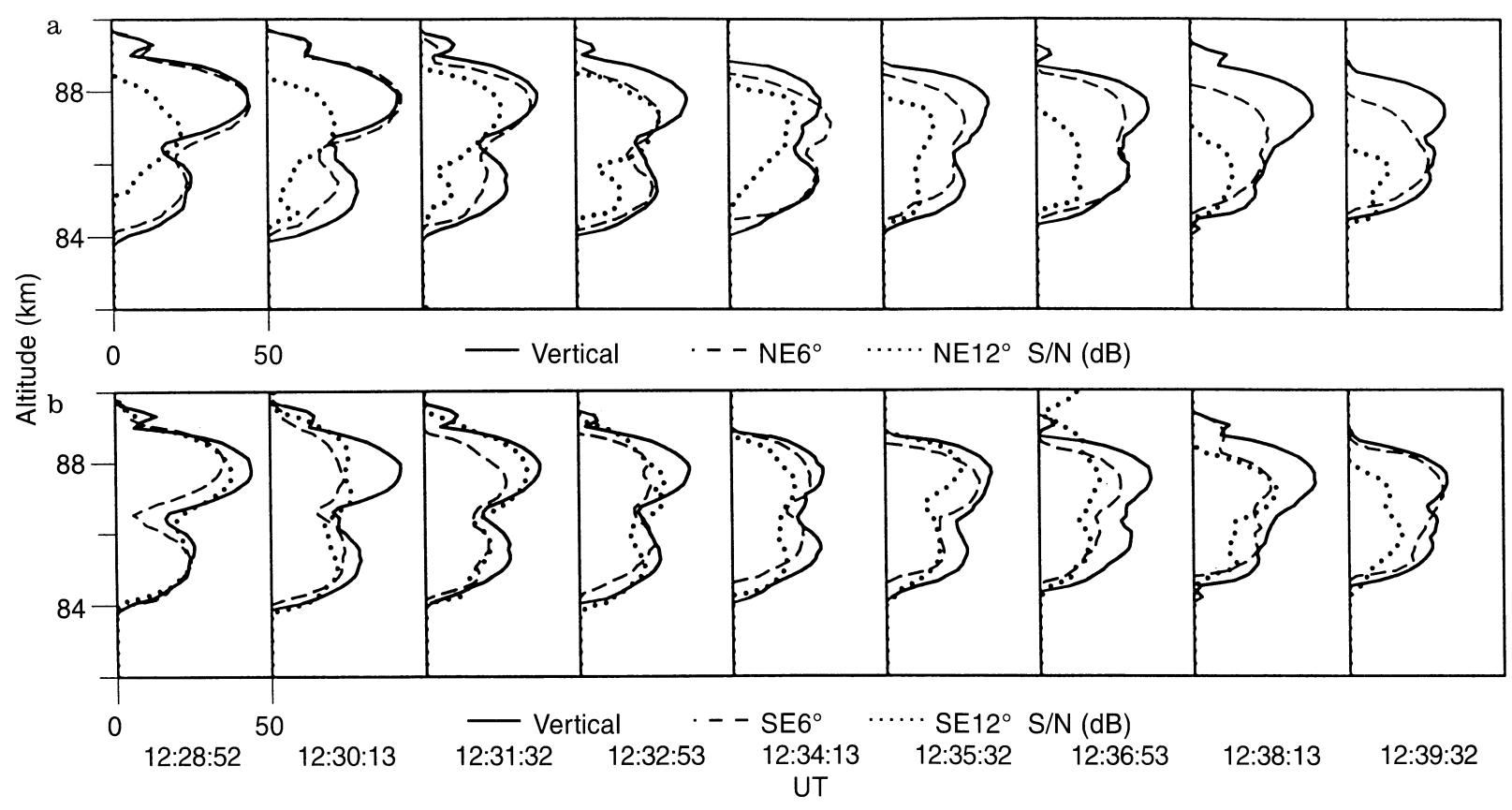

Fig. 8a, b. Altitude profiles of the $\mathrm{S} / \mathrm{N}$ for the vertical and $6^{\circ}$ and $12^{\circ}$ beams in a the NE azimuth and $\mathbf{b} \mathrm{SE}$ azimuth for nine consecutive cycles of observation on 8 July 1993 
aspect sensitivity of radar returns are a general feature of the observations made in the present investigation. In some instances the signal strengths observed by a beam directed $12^{\circ}$ off-vertical can exceed those observed in all other directions. It is not thought, therefore, that the nature of the scattering/reflection mechanism of the echo layer above the radar site can, in general, be inferred from a comparison of radar return signal strengths observed in different beam directions.

\section{Discussion}

Major differences between the mesopause regions at mid and polar latitudes are the lower temperatures and the more sharply defined minima at the latter. In addition, significant differences exist between the ionization conditions at the two latitude regions. Although photoionisation is the principal cause of electron production at mid-latitudes, particle precipitation also contributes at polar latitudes. In addition, the summer mesopause region is in continual sunlight at polar latitudes, but for a lesser time at mid-latitudes. Such differences, and the corresponding variations in electron concentrations, might be expected to give rise to variations in the characteristics of echo layers as a function of latitude. It has already been pointed out that unlike PMSEs, the appearance of MSEs is restricted in time; this arises in part from the reduction in electron density at night-time. The vertical movement described by PMSEs often shows long-term downward trends suggestive of the activity of the semi-diurnal tide and/or long-period gravity waves (Balsley et al., 1983; Fritts et al., 1988). In the present investigation, such long-term trends of movement are only observed in 2 out of 24 cases. Many of the observations of PMSEs have been made with a range resolution of $300 \mathrm{~m}$, whereas those made from Aberystwyth are generally at $1.2 \mathrm{~km}$ resolution. As has been pointed out in Sect. 4, some fine details of the altitude profiles are therefore likely to be lost in the Aberystwyth observations.

MSEs and PMSEs do, however, show many similarities and, therefore, observations made at $52.4^{\circ} \mathrm{N}$ in the present investigation will be discussed with reference to analogous phenomena associated with PMSEs. In the following discussion, attention will be focused on the observations of PMSEs at radar frequencies of about $50 \mathrm{MHz}$. Relatively strong echoes have also been observed at frequencies of $224 \mathrm{MHz}$ (Hoppe et al., 1988, 1990; Röttger and La Hoz, 1990; Röttger et al., 1990a, b), $933 \mathrm{MHz}$ (Röttger et al., 1990b) and $1.29 \mathrm{GHz}$ (Cho et al., 1992), but the mechanisms of return might be different at the higher frequencies (e.g. Cho and Kelley, 1993).

There are considerable difficulties in studying the summer mesopause region at mid and polar latitudes. VHF radar returns at a given time are generally limited in altitude coverage to, at most, a few kilometers, but in some cases they have been complemented by in situ rocket observations. Three major campaigns have been conducted which combine simultaneous rocket and radar studies of the polar summer mesosphere; the Structure and Atmospheric Turbulence Environment (STATE) campaign in 1983 (Ulwick et al., 1988), the Middle Atmosphere Co-operation/Summer in Northern Europe (MAC/SINE) campaign in 1987 (Thrane, 1990) and the Noctilucent Cloud-91 (NLC-91) campaign in 1991 (Goldberg et al., 1993). Such campaigns have provided the opportunity for examining the variation of relevant parameters along the rocket trajectories and have yielded an insight into the physical conditions that can exist at mesopause altitudes.

One of the main uncertainties concerning MSEs and PMSEs is the relative importance of backscatter and Fresnel reflection. In several instances of double-structure PMSEs, both mechanisms have been cited as being responsible in order to account for the differences between the natures of the two layers (Cho et al., 1993; Lübken et al., 1993; Miller et al., 1993; Ulwick et al., 1993). Radar returns from PMSEs that show large aspect sensitivity have been attributed to Fresnel reflection, and those that show low aspect sensitivity have been interpreted in terms of backscatter (Cho et al., 1993). It was shown in the previous section that the aspect sensitivity of radar returns from MSEs can be dominated by spatial variations of the radar crosssection, even for a given angle of incidence at different azimuths. It is not certain whether the same is true for PMSE layers; Miller et al. (1993) report a particular case for which they believe it to be.

It should be borne in mind that the rocket and radar measurements in the campaigns just cited were not colocated. Although the STATE radar and rocket observations, at the same altitude, had a maximum horizontal separation of $10 \mathrm{~km}$ (Ulwick et al., 1988), the minimum horizontal separation was $20 \mathrm{~km}$ for the MAC/SINE campaign (Inhester et al., 1990) and $13.3 \mathrm{~km}$ for the NLC-91 campaign (Lübken et al., 1993); the maximum horizontal separations for the latter two campaigns were in excess of $50 \mathrm{~km}$. Furthermore, given the extremely dynamic nature of MSEs and PMSEs, measurements from any single rocket observation will only be representative of the atmosphere at that particular sampling time and place. It has been shown for MSEs that in addition to changes of the radar signal strength, the altitude and rate of vertical motion can show significant variations over time-scales of minutes and over horizontal spatial scales of several kilometers. These suggest corresponding variations in the nature of the atmosphere at the mid-latitude mesopause region. It is not clear whether the same temporal and spatial scales are present in PMSEs and the atmosphere at the polar mesopause. It is therefore recommended that the multibeam observations of PMSE layers in previous campaigns be repeated in future exercises but, more importantly, that the horizontal separation between rocket and radar measurements be minimised.

It was shown in Sect. 4 that sharp changes with altitude of the horizontal wind speed and direction and of the vertical velocity, together with a minimum of horizontal wind speed, are observed at the bifurcation level of MSE layers. These features appear to be 
analogous to a phenomenon observed in the polar mesosphere during both summer and winter, as identified in the trajectories of radar chaff released from rockets (von Zahn and Widdel, 1985; Widdel and von Zahn, 1990; Wu and Widdel, 1992). It was found that the observed wind shear tended to be concentrated in narrow altitude regions (von Zahn and Widdel, 1985). Widdel and von Zahn (1990) defined 'wind corners' as narrow regions, much less than $1 \mathrm{~km}$ in vertical extent, within which there is a very strong directional shear of greater than $5^{\circ} / 100 \mathrm{~m}$ and at which the horizontal speed is a minimum. Those corners observed during the winter were typically below $80-\mathrm{km}$ altitude, whereas those observed during the summer were found exclusively above this altitude (Widdel and von Zahn, 1990). Similar features can be clearly seen at the bifurcation level of the echo layer shown in Fig. 5; the directional shear, Fig. 5d, is typically much greater than $5^{\circ} / 100 \mathrm{~m}$. Furthermore, Widdel and von Zahn (1990) reported that the vertical gradient of the vertical wind velocity usually showed a maximum at the same altitude. Such maxima are also apparent at the bifurcation level of the echo layers shown in Figs. $6 \mathrm{~b}$ and $7 \mathrm{~b}$.

In several cases of wind-corner observations, the corresponding temperature structure was obtained from falling spheres released shortly before the chaff, thus allowing calculations of the gradient Richardson number, Ri (Widdel and von Zahn, 1990). The altitudes of Ri minima, with values close to or less than $1 / 4$, were found to coincide with, or to be slightly separated from those at which wind corners occurred (Thrane et al., 1987; Widdel and von Zahn, 1990). Wu and Widdel (1992) also observed large variances of vertical velocity, indicative of turbulent activity, where the corresponding values of $\mathrm{Ri}$ were close to or less than $1 / 4$. Although the altitudes of wind corners and PMSEs were found to be in good agreement at altitudes of less than $86 \mathrm{~km}$, no clear correspondence could be found above this level (Widdel and von Zahn, 1990). It has already been mentioned in Sect.4 that the maximum vertical wind shears in Fig. 5e, occurring at the bifurcation level, are thought to be sufficiently large to make the region dynamically unstable. This result suggests that radar returns from the bifurcation level, in this particular case, are a result of backscatter rather than Fresnel reflection.

Broad spectral widths of radar returns from PMSEs have been interpreted as representing backscatter from regions of turbulence (Cho et al., 1993; Ulwick et al., 1993). The maximum vertical spectral (half-power full) widths of between 5 and $10 \mathrm{~m} / \mathrm{s}$ shown in Fig. $5 \mathrm{f}$ often occur at the bifurcation level. In general, spectral width measurements can include contributions from changes in the vertical wind during the time of observation and across the vertical extent of the radar volume (Murphy et al., 1994), beam broadening, and fluctuations of the vertical-velocity caused by turbulent activity (Hocking, 1983). Since each Doppler spectrum for the Aberystwyth radar represents observations made over $10.5 \mathrm{~s}$, considerably shorter than the Brunt-Väisälä period, it is assumed that any changes in the vertical wind during this time, and therefore any corresponding spectral broadening, are negligible (Murphy et al., 1994). It is likely that the sharp changes in vertical velocity at the bifurcation level, which occur within a vertical extent of $1.2 \mathrm{~km}$, the range resolution of the radar observations, give rise to some contamination of the observed spectral width. Nevertheless, enhanced spectral widths can be seen at the bifurcation level in Fig. 5f even during particular cycles for which the change of vertical velocity is very small. Beam broadening is known to dominate vertical beam spectral widths for radar returns from the troposphere and the lower stratosphere (Hocking, 1985). Since some uncertainty exists in the validity of the horizontal wind speed, as shown in Sect. 3 , no attempt has been made to correct the vertical spectral widths for beam broadening. However, for the typical wind speed of $30 \mathrm{~m} / \mathrm{s}$ seen in Fig. $5 \mathrm{~b}$, beam broadening would account for a spectral width of $1.1 \mathrm{~m} /$ $\mathrm{s}$, a contribution of less than $5 \%$ to the total observed spectral width of between 5 and $10 \mathrm{~m} / \mathrm{s}$, Fig. 5f. Using specific values of wind speed and observed spectral width, it can be shown that the contribution of beam broadening at the bifurcation level is typically less than $1 \%$. It is reasonable to assume, therefore, that the enhanced spectral width is additional proof that backscatter is responsible for radar returns from the bifurcation level and that the turbulence is most intense there also.

At either side of the bifurcation level, beam-broadening contributions to the observed spectral widths are, in general, still relatively small, although they can account for up to several tens of $\%$ of the smaller widths. It is therefore not clear whether radar returns from those regions of the echo layer represent Fresnel reflection or backscatter from regions of weak turbulence.

The profiles $a$ and $f$ in Fig. 5 suggest an anticorrelation between vertical signal strength and spectral width at the bifurcation level. Such a condition has been cited as an indication of radar returns by Fresnel reflection, whereas a correlation between signal strength and spectral width was expected for radar returns by backscatter (Thomas et al., 1992; Miller et al., 1993). Backscattered signal strength, however, depends on both the degree of turbulence and on the vertical gradient of potential refractive index (Ottersten, 1969). At mesospheric altitudes, variations in refractive index are dominated by changes in the electron density (Woodman and Guillen, 1974). In situ measurements at polar latitudes have detected deep 'bite-outs' of electron density, in which depletions by an order of magnitude occur over a sharply bounded layer of approximately $1 \mathrm{~km}$ vertical extent (Ulwick et al., 1988; Inhester et al., 1990; Inhester and Ulwick, 1992). If a minimum of electron density occurs between the two maxima in the altitude variation of $\mathrm{S} / \mathrm{N}$ in MSEs, as in the model of Klostermeyer (1994) for PMSEs, it is possible that the vertical gradients of electron density at either side could outweigh the decreases in turbulence intensity suggested by the smaller vertical shears and spectral widths, Fig. 5e, f. This would be consistent with the stronger backscatter from either side of the bifurcation level. 
Röttger et al. (1990a) reported sharp changes in the Doppler shift associated with PMSEs observed by the vertical beam of the EISCAT 224-MHz radar. These occurred over short time-intervals, of the order of a minute, and over limited altitude ranges. A similar phenomenon was reported for lower VHF observations of PMSEs by Cho et al. (1993). One explanation given was that Fresnel reflection was responsible for the radar returns and that the sharp changes were caused by the advection through the radar beam of a non-horizontal reflecting layer which had been distorted by gravitywave activity. It has been shown in the present study that sharp changes of vertical velocity occur at the bifurcation level of MSEs and, furthermore, that the altitude of the bifurcation level can vary as a function of time; the latter point is particularly clear in Fig. 7a. For observations at a fixed altitude, sharp changes of vertical velocity might be expected to occur over a short timeperiod if the altitude of the bifurcation changed and passed through that particular altitude.

It is known that PMSEs and MSEs are associated with the extremely low temperatures at the summer mesopause (Inhester et al., 1994; Thomas et al., 1996). Moreover, it is commonly believed that they are in some way linked to layers of ice crystals which can form at these temperatures (Kelley et al., 1987; Hall, 1990; Wälchi et al., 1993). Klostermeyer (1994) suggested that the upper and lower sections of double PMSEs might correspond to the bottom and top boundaries of such ice layers. From Sect. 4, it follows that the two boundaries of the ice layer would behave quasi-independently and the separation between them would vary as a function of time.

\section{Conclusions}

Most of the altitude profiles of $\mathrm{S} / \mathrm{N}$ for mesospheric summer echo layers observed from Aberystwyth show evidence of a bifurcation. Sharp changes with altitude of the horizontal wind speed and direction and of the vertical velocity, together with a minimum of horizontal wind speed, are observed at the bifurcation level. This phenomenon appears to be analogous to 'wind corners' observed in the polar mesosphere. The large vertical wind shears and enhanced vertical spectral widths at the bifurcation level suggest that it is turbulent and that backscatter is responsible for the radar returns from this level. It cannot be established whether backscatter or Fresnel reflection is responsible for radar returns from either side of the bifurcation level.

The altitude and sense of vertical movement of the echo layers can vary over time-scales of minutes and horizontal scales of kilometers. In some cases, these variations can dominate the aspect sensitivity of the radar returns. The latter cannot, therefore, necessarily be used to distinguish between radar returns by Fresnel reflection and turbulent backscatter.

Acknowledgements. Topical Editor L. Eymard thanks P. Chilson for his help in evaluating this paper.

\section{References}

Balsley, B. B., W. L. Ecklund, and D. C. Fritts, VHF echoes from high-latitude mesosphere and lower thermosphere: observations and interpretations, J. Atmos. Sci., 40, 2451-2466, 1983.

Cho, J. Y. N., and M. C. Kelley, Polar mesosphere summer radar echoes: observations and current theories, Rev. Geophys., 31, 243-265, 1993.

Cho., J. Y. N., M. C. Kelley, and C. J. Heinselman, Enhancement of Thomson scatter by charged aerosols in the polar mesosphere: measurements with a 1.29-GHz radar, Geophys. Res. Lett., 19, 1097-1100, 1992.

Cho, J. Y. N., W. E. Swartz, M. C. Kelley, and C. A. Miller, CUPRI observations of PMSE during Salvo B of NLC-91: evidance of both partial reflection and turbulent scatter, Geophys. Res. Lett., 20, 2291-2294, 1993.

Czechowsky, P., R. Rüster, and G. Schmidt, Variations of mesospheric structures in different seasons, Geophys. Res. Lett., 6 , 459-462, 1979.

Czechowsky, P., I. Reid, and R. Rüster, VHF radar measurements of the aspect sensitivity of the summer polar mesopause echoes over Andenes $\left(69^{\circ} \mathrm{N}, 16^{\circ} \mathrm{E}\right)$ Norway, Geophys. Res. Lett., 15, 1259-1262, 1988.

Czechowsky, P., I. Reid, R. Rüster, and G. Schmidt, VHF radar echoes observed in the summer and winter polar mesosphere over Andya, Norway, J. Geophys. Res., 94, 5199-5217, 1989.

Ecklund, W.L., and B. B. Balsley, Long-term observations of the arctic mesosphere with the MST radar at Poker Flat, Alaska, $J$. Geophys. Res., 86, 7775-7780, 1981.

Franke, S. J., J. Röttger, C. La Hoz, and C. H. Liu, Frequency domain interferometry of polar summer echoes with the EISCAT VHF radar, Radio Sci., 27, 417-428, 1992.

Fritts, D. C., S. A. Smith, B. B. Balsley, and C. R. Phllbrik, Evidence of gravity wave saturation and local turbulence production in the summer mesosphere and lower thermosphere during the STATE experiment, J. Geophys. Res., 93, 7015-7025, 1988.

Fritts, D. C., U.-P. Hoppe, and B, Inhester, A study of the vertical motion field near the high-latitude summer mesopause during MAC/SINE. J. Atmos. Terr. Phys., 52, 927-938, 1990.

Gage, K. S., and B. B. Balsley, On the scattering and reflection mechanisms contributing to clear air radar echoes from the troposphere, stratosphere and mesosphere, Radio Sci., 15, 243 257, 1980.

Goldberg, R. A., E. Kopp, G. Witt, and W. E. Swartz, An overview of NLC-91: a rocket/radar study of the polar summer mesosphere, Geophys. Res. Lett., 20, 2283-2286, 1993.

Hall, C. M., Modification of the energy-wave number spectrum for heavy proton hydrates as tracers for isotropic turbulence at the summer mesopause, J. Geophys. Res., 95, 5549-5556, 1990.

Harper, R. M., and R. F. Woodman, Preliminary multiheight radar observations of waves and winds in the mesosphere over Jicamarca, J. Atmos. Terr. Phys., 39, 959-963, 1977.

Hocking, W. K., On the extraction of atmospheric turbulence parameters from radar backscatter Doppler spectra-1 Theory, J. Atmos. Terr. Phys., 45, 89-102, 1983.

Hocking, W. K., Measurement of turbulent energy dissipation rates in the middle atmosphere by radar techniques: a review, Radio Sci., 20, 1403-1422, 1985.

Hocking, W. K., R. Rüster, and P. Czechowsky, Absolute reflectivities and aspect sensitivities of VHF radio wave scatterers measured with SOUSY radar J. Atmos. Terr. Phys., 48, 131144, 1986

Hooper, D., and L. Thomas, Aspect sensitivity of VHF scatterers in the troposphere from comparisons of powers in off-vertical beams, J. Atmos. Terr. Phys., 57, 655-663, 1995.

Hoppe U.-P., and D. C. Fritts,. High-resolution measurements of vertical velocity with the European incoherent-scatter VHF radar. 1. Motion field characteristics and measurement biases, J. Geophys. Res., 100, 16813-16825, 1995. 
Hoppe, U.-P., C. Hall, and J. Röttger, First observations of summer polar mesospheric backscatter with a $224-\mathrm{MHz}$ radar, Geophys. Res. Lett., 15, 28-31, 1988.

Hoppe, U.-P., D. C. Fritts, I. M. Reid, P. Czechowsky, C. M. Hall, and T. L. Hansen, Multiple-frequency studies of the highlatitude summer mesosphere: implications for scattering processes. J. Atoms. Terr. Phys., 52, 907-926, 1990.

Inhester, B., and J. C. Ulwick, Combined rocket and radar observations of anisotropic fluctuations in the mesosphere.,Adv. Space Res., 10, 165-168, 1992.

Inhester, B., J. C. Ulwick, J. Cho, M. C. Kelley, and G. Schmidt, Consistency of rocket and radar electron density observations: implications about the anisotropy of mesospheric turbulence, $J$. Atmos. Terr. Phys., 52, 855-873, 1990.

Inhester, B., J. Klostermeyer, F. J. Lübken, and U. von Zahn, Evidence for ice clouds causing polar mesospheric summer echoes, J. Geophys. Res., 99, 20937-20954, 1994.

Kelley, M. C., D. T. Fariey, and J. Röttger, The effect of cluster ions on anomalous VHF backscatter from the summer polar mesosphere, Geophys. Res. Lett., 14, 1031-1034, 1987.

Kelley, M. C., J. C. Ulwick, J. Röttger, B. Inhester, T. Hall, and T. Blix, Intense turbulence in the polar mesosphere: rocket and radar measurements, J. Atmos. Terr. Phys., 52, 875-891, 1990.

Klostermeyer, J., A two-ion ice particle model of the polar summer mesopause, J. Geophys. Res., 99, 5487-5497, 1994.

Kudeki, E, and G. Stitt, Frequency domain interferometry: a highresolution radar technique for studies of atmospheric turbulence, Geophys. Res. Lett., 14, 198-201, 1987.

Lübken, F. J., G. Lehmacher, T. Blix, U.-P. Hoppe, E. Thrane, J. Cho, and W. Swartz, First in situ observations of neutral and plasma density fluctuations within a PMSE layer. Geophys. Res. Lett., 20, 2311-2314, 1993.

Miller, C. A., W. E. Swartz, and J. Y. N. Cho, CUPRI observations of PMSE during Salvo C of NLC-91: evidence of a depressed mesopause temperature, Geophys. Res. Lett., 20, 2295-2298, 1993.

Murphy, D. J., W. K. Hockling, and D. C. Fritts, An assessment of the effect of gravity waves on the width or radar Doppler spectra, J. Atmos. Terr. Phys., 56, 17-29, 1994

Ottersten, H., Mean vertical gradient of potential refractive index in turbulent mixing and radar detection of CAT, Radio Sci., $\mathbf{4}$, 1247-1249, 1969

Reid, I. M., P. Czechowsky, R. Rüster, and G. Schmidt, First VHF radar measurements of mesopause summer echoes at midlatitudes, Geophys. Res. Lett., 16, 135-138, 1989.

Röttger, J., and C. La Hoz, Characteristics of Polar Mesosphere Summer Echoes (PMSE) observed with the EISCAT 224-MHz radar and possible explanations of their origin, J. Atmos. Terr. Phys., 52, 893-906, 1990.

Röttger, J., C. La Hoz, M. C. Kelley, U.-P. Hoppe, and C. Hall, The structure and dynamics of polar mesosphere summer echoes observed with the EISCAT 224-MHz radar, Geophys. Res. Lett., 15, 1353-1356, 1988.

Röttger, J., C. La Hoz, S. J. Franke, and C. H. Liu, Steepening of reflectively structures detected in high-resolution Doppler spectra of Polar Mesosphere Summer Echoes (PMSE) observed with the EISCAT 224-MHz radar, J. Atmos. Terr. Phys., 52, 939954, 1990a.

Röttger, J., M. T. Rietveid, C. La Hoz, T. Hall, M. C. Kelley, and W. E. Swartz, Polar Mesosphere Summer Echoes observed with the EISCAT 933-MHz radar and the CUPRI 46.5-MHz radar, their similarity to $224-\mathrm{MHz}$ radar echoes, and their relation to turbulence and electron density profiles, Radio Sci., 25, 671687, 1990b.

Rüster, R., P. Czechowsky, P. Hoffman, and W. Singer, Gravity wave signatures at mesospheric heights. Ann. Geophysicae, 14, 1186-1191, 1996.

Slater, K., A. D. Stevens, S. A. M. Permain, D. Eccles, A. J. Hall, R. G. T. Bennett, L. France, G. Roberts, Z. K. Olewicz, and L. Thomas. Overview of the MST radar system at Aberystwyth. Proc. Fifth Worksh Technical and Scientific Aspects of MST radar, Ed. B. Edwards, SCOSTEP, University of Illinois, Urbana, USA, pp. 479-482, 1992.

Stitt, G., and E. Kudeki, Interferometric cross-spectral studies of mesospheric scattering layers, Radio Sci., 26, 783-799, 1990.

Swartz W. E., J. Y. N. Cho, and A. C. Miller, CUPRI system configuration for NLC-91 and observations of PMSE during Salvo A, Geophys. Res. Lett., 20, 2287-2290, 1993.

Thomas, L., and I. Astin, The form of metre-scale turbulence at mesopause heights in summer, J. Atmos. Terr. Phys., 56, 467478, 1994.

Thomas, L., I. Astin, and I. T. Prichard, The characteristics of VHF echoes from the summer mesopause region at mid-latitudes, $J$. Atmos. Terr. Phys., 54, 969-977, 1992.

Thomas, L., A. K. P. Marsh, D. P. Wareing, I. Astin, and H. Chandra, VHF echoes from mid-latitude mesosphere and the thermal structure observed by lidar, J. Geophys. Res. Lett., 101, 12867-12877, 1996.

Thrane, E., Studies of middle atmosphere dynamics: the research projects Middle Atmosphere Cooperation/Summer in Northern Europe (MAC/SINE), and MAC/EPSILON, J. Atmos. Terr. Phys., 52, 815-825, 1990.

Thrane, E. V., T. A. Blix, C. Hall, T. L. Hansen, U. von Zahn, W. Meyer, P. Czechowsky, G. Schmidt, H.-U. Widdel, and A. Neumann, Small-scale structure and turbulence in the mesosphere and lower thermosphere at high latitudes, J. Atmos. Terr. Phys., 49, 751-762, 1987.

Ulwick, J. C., K. D. Baker, M. C. Kelley, B. B. Balsley, and W. L. Ecklund, Comparison of simultaneous MST radar and electron density probe measurements during STATE, J. Geophys. Res., 93, 6989-7000, 1988

Ulwick, J. C., M. C. Kelley, C. Alcala, T. A. Blix, and E. V. Thrane, Evidence for two different structuring and scattering mechanisms and the associated role of aerosols in the polar summer mesopause, Geophys. Res. Lett., 20, 2307-2310, 1993.

von Zahn, U., and H.-U. Widdel, Wind corners in the winter mesosphere, Geophys. Res. Lett., 12, 673-676, 1985.

Wälchi, U., J. Stegman, G. Witt, J. Y. N. Cho, C. A. Miller, M. C. Kelley, and W. E. Swartz, First height comparison of noctilucent clouds and simultaneous PMSE, Geophys. Res. Lett., 20, 2845-2848, 1993

Watkins, B. J., C. R. Philbrick, and B. B. Balsley, Turbulence energy dissipation rates and inner scale sizes from rocket and radar data, J. Geophys. Res., 93, 7009-7014, 1988.

Widdel, H.-U., and U. von Zahn, Wind corner observations in the $70-100-\mathrm{km}$ altitude range as observed at Andenes (69 latitude), J. Atmos. Terr. Phys., 52, 995-1015, 1990.

Woodman, R. F., and A. Guillen, Radar observations of winds and turbulence in the stratosphere, and mesosphere, J. Atmos. Sci., 31, 493-505, 1974.

Wu, Y.-F, and H.-U. Widdel, Structure of the atmosphere in the vicinity of VHF radar echoes in the mesosphere, Adv. Space Res., 12, 295-297, 1992. 